\title{
Frequency of Non-Medical Use of Methylphenidate (Ritalin) Among Medical Students of Zahedan University of Medical Sciences
}

\author{
Maryam Lashkaripour (iD ${ }^{1}$, Susan Dartomi ${ }^{2}$, Zahra Ghiasi (id ${ }^{1,},{ }^{*}$, Farzaneh Farajian-Mashhadi ${ }^{3}$ and \\ Narjes Sargolzaei ${ }^{4}$ \\ ${ }^{1}$ Department of Psychiatry, Zahedan University of Medical Sciences, Zahedan, IR Iran \\ ${ }^{2}$ School of Medicine, Zahedan University of Medical Sciences, Zahedan, IR Iran \\ ${ }^{3}$ Department of Pharmacy, Zahedan University of Medical Sciences, Zahedan, IR Iran \\ ${ }^{4}$ Department of Community Medicine, Zahedan University of Medical Sciences, Zahedan, IR Iran \\ "Corresponding author: Department of Psychiatry, Zahedan University of Medical Sciences, Zahedan, IR Iran. Email: linooshghiasi@gmail.com
}

Received 2018 September 28; Revised 2019 May 30; Accepted 2019 June 01.

\begin{abstract}
Background: Despite the therapeutic effects of methylphenidate, there are many reports of non-medical use, especially among students.

Objectives: The aim of this study was to investigate the frequency of non-medical use of methylphenidate among students of Zahedan University of Medical Sciences.

Patients and Methods: In this descriptive-analytic (cross-sectional) study, 561 students were selected through the convenient sampling method from Zahedan University of Medical Sciences during the 2015 - 2016 academic year. A researcher-made questionnaire was used to collect information. Data were analyzed using descriptivestatistics, chi-square (2) with a significance levelof 0.05 by SPSS software version 21.

Results: Of 561 students studied in this research, 108 persons (19.3\%) had a positive experience of non-medical use of methylphenidate, of which Occasional use was reported by 38 (6.8\%) students and $3(0.5 \%)$ students reported daily use. The highest rate of methylphenidate use was observed in medical assistants with a frequency of 37 persons (35.6\%) and persons with more than 30 years old with a frequency of 32.5\%. The frequency of non-medical use of methylphenidate in females is almost 2 times more than males (26.8\% versus $14.1 \%)$, in students who live in their own homes (27.9\%) was more, and the commonest cause of use was improving academic performance (13.9\%).

Conclusions: According to the high frequency of non-medical use of methylphenidate in students, the probability of methylphenidate consumption may increase in the future. With regard to possible complications, including dependence and abuse, there is a serious need for intervention to reduce the non-medical use of methylphenidate and the identification and treatment of side effects.
\end{abstract}

Keywords: Methylphenidate, Medical Students, Physician Assistants, Prescription Drug Misuse

\section{Background}

Drug abuse is one of the major problems that communities are faced with it around the world, and a lot of capitals spent to deal with its consequences. Drug abuse can also cause medical and psychological harm. According to the World Health Organization (WHO) reports, drug abuse rates among adolescents and young people are rising, and Iran is no exception to this. The population of addicts in the country is doubled every 10 years. Among young people, students in the first year of university education are specifically considered a high-risk group for drug abuse (1).

One of the substances that have a high potential for abuse is methylphenidate (Ritalin). Ritalin, like am- phetamines, is a psychostimulant and can increase consciousness and concentration. Many students use Ritalin to increase their attention $(2,3)$. Its consumption seems to help students to study more easily and feel good. Those who use Ritalin tend to increase their dose (4). Nonmedical use of prescription stimulants (NPS) is the use of a drug commonly applied to treat attention deficit hyperactivity disorder (ADHD) without prescribing a doctor or in a manner different from that of the doctor prescribed (5).

The more accepted definition of NPS is the use of medication without prescribing for a person. In this way, the drug can be obtained in various ways, including free taking or purchase, either from the person who prescribes it 
or does not prescribe it, or by ordering it from internet sources without a legal prescription (6). Although Ritalin seems to be relatively safe, misuse or abuse of any stimulant can result in complications (7). Ritalin is classified in the category of drugs with a high potential for excessive consumption and can lead to severe psychological and physical dependence (8).

As a result of raising awareness among doctors about ADHD, the administration of methylphenidate has been increased over the past few decades, especially for adults. Therefore, the number of young people and adults who intake medication for ADHD is rising. Following an increase in drug administration, access to medicine for nonmedical use prescription has also increased (7). Accordingly, methylphenidate abuse seems to be a serious problem among students. Medical students are likely to be more susceptible to alcohol and narcotic drugs because of exposure to intensive training programs, fear, and anxiety from failure (9).

Over the years, researchers have been investigating the prevalence of methylphenidate abuse among medical students. Habibzadeh et al. studied 310 medical students of Tabriz University of Medical Sciences. The lifetime, last year, and last month prevalence of methylphenidate consumption were $8.7 \%, 6.5 \%$, and $1 \%$, respectively (10). In Khademi and Shariat's research, the frequency of nonmedical use of methylphenidate was evaluated in the assistants of Tehran University of Medical Sciences. According to their findings, the lifetime, last year, and last month prevalence were $48 \%, 23 \%$, and $6.6 \%$, respectively (11). Vakili and Nilipour conducted a study to evaluate the prevalence of Ritalin abuse among 468 medical students of Najaf Abad University. Sixty-five (13.9\%) students had at least once Ritalin use. The majority of them were male students and between 18 to 25 years old, and the most common causes of Ritalin consumption were decreased sleep, and to increase concentration and energy (12). Ataei et al. studied 264 students from Isfahan University of Medical Sciences and reported a $6.6 \%$ rate of Ritalin abuse among students; the consumption was higher in men than in women, and the main reason for consumption methylphenidate was preparing for the assistant exam (13).

A study was conducted by Jalilian et al. on 385 students of Kermanshah University of Medical Sciences. The lifetime frequency of methylphenidate abuse has been reported at $5.4 \%$. In this study, focusing on lessons was mentioned as the main cause of abuse (14).

In the same year, another study by Eslami and his colleagues was conducted among 264 students of Isfahan University of Medical Science. The lifetime prevalence of Ritalin abuse among students was $6.6 \%$. In this study, the rate of Ritalin abuse was higher in Ph.D. students com- pared to undergraduate students, which could be owing to a greater awareness of its benefits or easier access to methylphenidate. Also, according to this study, the attitude toward the consequences of abuse such as improving academic performance is positive in the consumers (15).

This study examines the frequency of non-medical use of methylphenidate (Ritalin) among medical students of Zahedan University of Medical Sciences. Also, given the use of this drug can initiate the use of other stimulant drugs, and access to the other stimulant drugs in this region is higher than the other regions of the country, as well as the higher risk of dependence, examining non-medical use of methylphenidate in this area is very important. With respect to the precise frequency, we can plan more precisely and thus we can efficiently prevent the dependence of stimulant medications.

\section{Objectives}

Owing to the importance of understanding the conditions related to non-medical use of methylphenidate and providing the preventive programs, the aim of this study was to evaluate and compare the frequency of non-medical use of methylphenidate among medical students at various stages, as well as factors related to their tendency toward non-medical use of methylphenidate.

\section{Patients and Methods}

This descriptive-analytic (cross-sectional) study was conducted among male and female students of different age groups of Zahedan University of Medical Sciences in 2016. To calculate the sample size, we followed Morton and Stockton study (4). Considering the sample size, we decided to study all interns, trainees, and assistants in 2016, and the minimum sample size in each group was determined 100 individuals. Finally, 561 students were recruited by the convenience sampling method.

Students had to complete at least one month of their academic term. Participation in the study was voluntary and students could withdraw from the study at any point. This study was approved by the Ethics Committee of Zahedan University of Medical Sciences and all of the University's criteria for its implementation were considered. A researcher-made form was used to collect demographic data and the information needed for the purposes of this study. At the beginning of the questionnaire, the aim of this study was explained, and the questionnaires were anonymous and the participants were assured of the confidentiality of the information. In order to prevent inaccurate reporting of information, a folder was provided 
that students could place their questionnaire among other questionnaires so disclosure of information by the questionnaire receiver was impossible. After the approval of the study, we asked the permission of the managers of each department. Subsequently, for completing the researchermade questionnaire by trainees, we went to theoretical courses, and after explaining the purpose of the study, the questionnaire was delivered to the trainees. For interns at the beginning of the semester, the questionnaires were given to the internship educators. For completing the researcher-made questionnaire by assistants, after coordination, the questionnaire was delivered to the senior assistant in each clinical field. After that the questionnaires were completed by the students, the questionnaires were collected from each part. Data were analyzed using descriptive statistics, chi-square $\left(\chi^{2}\right)$ with a significance level of 0.05 by SPSS software version 21 .

\section{Results}

Of the 561 questionnaires completed by the students, $333(59.4 \%)$ were male, and $228(40.6 \%)$ were female. The average age of the students was $24.56 \pm 4.92$. The sample population consisted of 106 (18.89\%) undergraduate students, $97(17.29 \%)$ physiopathology's students, $147(26.2 \%)$ trainees, 107 (19.07\%) interns and 104 (18.53\%) assistant. Also, 408 (72.7\%) participants were single and 153 (27.3\%) were married. Regarding the living conditions, 204 (36.4\%) students lived with the family, 253 (45.1\%) in the dormitory, and 104 $(18.5 \%)$ in their own homes.

Regarding the frequency of non-medical use of prescription, $108(19.3 \%)$ students reported a positive experience. Of 108 students who reported using methylphenidate during their lifetime, 67 (11.9\%) students reported consumption of Ritalin only one or two times a lifetime. Occasional use was reported by $38(6.8 \%)$ students and $3(0.5 \%)$ students reported daily use. The rate of positive experience of methylphenidate consumption in the basic science group was 9.4\% (10 individuals), in the physiopathology group was $17.5 \%$ (17 individuals), in trainees was 18.4\% (27 individuals), in interns was 15.9\% (17 individuals), and in assistants was $35.6 \%$ (37 individuals).

Regarding the frequency of non-medical use of methylphenidate (Ritalin) in the students, based on age and type of consumption, the chi-square test at a significance level of $0.05 \%$ showed significant differences. Results are shown in Table 1.

Regarding the frequency of non-medical use of methylphenidate (Ritalin) in the students, based on sex, chi-square test at a significance level of $0.05 \%$ showed that methylphenidate consumption was significantly higher in females (Table 2).
Regarding the frequency of non-medical use of methylphenidate (Ritalin) in the students, based on the status of residence, the chi-square test at a significance level of $0.05 \%$ showed that there is no significant difference (Table 3).

Regarding the frequency of non-medical use of methylphenidate (Ritalin) in the students, based on the marital status, the chi-square test showed significant differences between the students (Table 4).

In order to determine the most common reason for non-medical use of Ritalin in the students of Zahedan University of Medical Sciences, 68 students (37.98\%) reported an improvement in academic performance, 59 students (32.96\%) reported awakening, 29 students (16.2\%) reported curiosity. Euphoria as another cause is reported by 11 students (6.14\%). Increased libido was reported by 3 (1.67\%) students. None of the participants reported weight loss as a reason for methylphenidate use. Nine (5.02\%) students mentioned other reasons. These findings are summarized in Table 5.

\section{Discussion}

The aim of this study was to investigate the frequency of non-medical use of methylphenidate (Ritalin) in medical students in Zahedan University of Medical Sciences. The findings showed that the rate of methylphenidate use in the lifetime was 108 (19.3\%) individuals, one or two times consumption in a lifetime based on self-report was 67 (11.9\%) individuals, occasional consumption was 38 (6.8\%) individuals and $3(0.5 \%)$ individuals had daily use. These results are consistent with the results of various studies (6, 15). However, the study of Khademi and Shariat (11) estimated that the frequency of lifetime uses was higher.

Also, in another study that examined the level of nonmedical use of Ritalin among medical students in the Free State (2017), the rate of methylphenidate use in the lifetime was $11 \%$ (9). In explaining this result, it can be said that the stresses and tensions that assistants and trainees are undergoing for their tests, as well as intense competition between medical students, are effective factors in the tendency for methylphenidate abuse. In addition, the stress imposed on students at these stages can lead to depression, which can be effective in the tendency of students to abuse stimulant drugs (11).

The highest non-medical use of methylphenidate was in the age group of fewer than 25 years old with a frequency of 64 (59.25\%). As reported by Khademi and Shariat with increasing the age, the probability of abuse increases, and younger subjects are unlikely to have any previous experience of consumption. In older age groups, in most cases, participants used one or two times methylphenidate 


\begin{tabular}{|c|c|c|c|c|c|}
\hline \multirow[t]{2}{*}{ Age range } & \multicolumn{3}{|c|}{ Consumption Type } & \multirow[t]{2}{*}{ Total } & \multirow[t]{2}{*}{ P Value } \\
\hline & One or Two Times Throughout Life & Occasional Consumption & Daily Consumption & & \\
\hline$<\mathbf{2 5}$ & $37(57.81)$ & $24(37.5)$ & $3(4.68)$ & $64(100)$ & \\
\hline $25-30$ & $13(68.42)$ & $6(31.57)$ & $0(0)$ & $19(100)$ & $<0.001$ \\
\hline $30<$ & $17(68)$ & $8(32)$ & $0(0)$ & $25(100)$ & \\
\hline
\end{tabular}

${ }^{\mathrm{a}}$ Values are expressed as No. (\%).

\begin{tabular}{|c|c|c|c|c|c|}
\hline \multirow[t]{2}{*}{ Gender } & \multicolumn{3}{|c|}{ Consumption Type } & \multirow[t]{2}{*}{ Total } & \multirow[t]{2}{*}{ P Value } \\
\hline & One or Two Times Throughout Life & Occasional Consumption & Daily Consumption & & \\
\hline Male & $40(85.1)$ & $7(14.89)$ & $0(0)$ & $47(100)$ & \multirow{2}{*}{$<0.001$} \\
\hline Female & $27(44.26)$ & $31(50.81)$ & $3(4.91)$ & $61(100)$ & \\
\hline
\end{tabular}

${ }^{\mathrm{a}}$ Values are expressed as No. (\%).

Table 3. Frequency of Use Based on the Status of Residence ${ }^{a}$

\begin{tabular}{lccc}
\hline Status of Residence & Positive Experience of Use & Negative Experience of Use & P Value \\
\hline Live with family & $35(17.2)$ & $169(82.8)$ & $204(100)$ \\
Live in dormitory & $44(17.4)$ & $209(82.6)$ & $253(100)$ \\
\hline Live in personal home & $29(27.9)$ & $75(72.1)$ & $104(100)$ \\
\hline
\end{tabular}

${ }^{\mathrm{a}}$ Values are expressed as No. (\%).

Table 4. Frequency of Use Based on Marital Status ${ }^{\mathrm{a}}$

\begin{tabular}{lccc}
\hline Marital Status & Positive Experience of Use & Negative Experience of Use & P Value \\
\hline Single & $65(15.9)$ & $343(84.1)$ & $408(100)$ \\
Married & $43(28.1)$ & $110(71.9)$ & $153(100)$ \\
\hline
\end{tabular}

${ }^{\mathrm{a}}$ Values are expressed as No. (\%).

Table 5. Frequency of Reasons for Non-Medical Use of Ritalin ${ }^{a}$

\begin{tabular}{lccccccc}
\hline Variable & Educational Performance Improvement & Euphoria & Curiosity & Awakening & Libido Increase & Weight Loss & Other Reasons \\
\hline Number & 68 & 11 & 29 & 59 & 3 & 0 \\
Percent & 37.98 & 6.14 & 16.20 & 32.96 & 1.67 & 0 \\
\hline
\end{tabular}

${ }^{\mathrm{a}}$ Some students mentioned several reasons to use.

and then left it, but younger people did not have either methylphenidate use before or had an occasional or daily use (11). Higher methylphenidate abuse is expected at an older age, but daily and occasional usages in younger individuals need more investigation.

The frequency of non-medical use of methylphenidate in females was almost two times more than males (61 versus 47), which is significantly different from the results of previous studies. In the study of Khademi and Shariat (11) the frequency of methylphenidate abuse was higher in males (29\% versus 13.6\%). Habibzadeh et al. (10) ex- amined the non-medical use of methylphenidate in Isfahan University of Medical Sciences. They reported that methylphenidate abuse in male was $92.5 \%$, compared with $7.5 \%$ in females. Findings of other studies have not reported gender differences in this regard, or inconsistent with the findings of the recently-mentioned study, reporting a higher level of abuse among males. This difference may result from the fact that girls, in order to cope with stressful situations, have a greater tendency to use stimulants to improve their performance. In addition, males have access to various substances for abuse that it may be 
involved in this difference. More studies are recommended in this regard $(11,16)$.

In the current study, non-medical use of methylphenidate was higher in students living at personal home (27.9\%). Non-medical use of methylphenidate was not significantly different between students living in dormitories and with family (17.4\% versus $17.2 \%)$. In a study conducted by Rezahosseini et al. at Rafsanjan University of Medical Sciences, there is the same findings that drug abuse and alcohol addiction were higher among students residing in a personal rented home. This can be due to the lack of control of parents in this group of students (17). Non-medical use of methylphenidate in married students was higher than unmarried students (28.1\% vs. $15.9 \%)$, owing to the higher frequency of non-medical use among assistants and the fact that the highest proportion of married students is among assistants (78.8\%), this finding may be justifiable.

In the present study, in relation to the reasons for nonmedical use, findings are consistent with the results of Jin et al. (9), and the study of Silveira Rda et al. (6) of which the most common cause of methylphenidate abuse was improving academic performance (67.9\%) and (68.7\%). Other reasons mentioned in these studies focused more on curiosity and awakening, which is consistent with the findings of this study (18).

According to the results of this study, non-medical use of methylphenidate in medical students is mainly aimed at improving academic performance. Living away from the family and specifically living in a private home can have a significant role in non-medical use of methylphenidate. Regarding the high prevalence of non-medical use of methylphenidate in trainees and assistants compared with other educational levels, pre-internship and assistance exams can be considered the most sensitive periods for acquaintance and the first non-medical use of methylphenidate. Considering that the main reason for methylphenidate abuse has been reported to improve academic performance, training reading skills and providing appropriate training programs for students can lead to beneficial results in the prevention of methylphenidate abuse.

Curiosity in young people is also a factor affecting the tendency for methylphenidate. Designing educational programs can answer many of the students' mental questions in this area. Overall, the present study suggests that non-medical use of methylphenidate is significantly high in medical students, which result in highly occasional nonmedical use of methylphenidate in younger students. The high rate of acceptance of the suggestions and comments from friends regarding the use of this drug in the young students enhances the probability of abuse in this age group. There is a serious need for intervention to reduce the non-medical use of prescription stimulants and the identification and treatment of side effects.

From our point of view, the medical curriculum should include methods for coping with stress as well as the consequences of improper use of methylphenidate, especially in the early semesters. Although further studies are needed to explore the perceptions and tendencies of medical students to methylphenidate abuse, according to previous studies, there is a more favorable attitude toward the positive consequences of methylphenidate abuse (including increased focus and attention, and improved academic performance) in relation to its negative consequences (the creation of dependency, the occurrence of psychological problems, etc.). Therefore, it seems that the negative attitude toward methylphenidate abuse should be emphasized in educational programs. The most important limitation of this study was self-assessment of the evaluation method, which can cause some people to deny their intake or report their intake less than the fact. In order to solve this problem, before submitting a questionnaire, a description of the purpose of the study and the confidentiality of information was provided.

\section{Footnotes}

Authors' Contribution: Study concept and design: Zahra Ghiasi, Maryam Lashkaripour, and Susan Dartomi; acquisition of data: Susan Dartomi; analysis and interpretation of data: Narjes Sargolzaei, Farzaneh Farajian-Mashhadi, and Susan Dartomi; drafting of the manuscript: Zahra Ghiasi; statistical analysis: Susan Dartomi and Maryam Lashkaripour.

Conflict of Interests: The authors declare no conflict of interests.

Ethical Considerations: ir.zaums.rec.12940414.

Funding/Support: This study was conducted without any financial support.

\section{References}

1. Jalilian F, Ataee M, Matin BK, Ahmadpanah M, Jouybari TA, Eslami AA, et al. Cognitive factors related to drug abuse among a sample of Iranian male medical college students. Glob J Health Sci. 2015;7(5):14351. doi: 10.5539/gjhs.v7n5p143. [PubMed: 26156919]. [PubMed Central: PMC4803908].

2. Outram SM. The use of methylphenidate among students: The future of enhancement? J Med Ethics. 2010;36(4):198-202. doi: 10.1136/jme.2009.034421. [PubMed: 20338928].

3. Sadock BJ, Sadock VA, Ruiz P. Kaplan \& sadock's comprehensive textbook of psychiatry. Philadelphia; 2009. 
4. Morton WA, Stockton GG. Methylphenidate abuse and psychiatric side effects. Prim Care Companion J Clin Psychiatry. 2000;2(5):159-64. doi: 10.4088/pcc.v02n0502. [PubMed: 15014637]. [PubMed Central: PMC181133].

5. Arria AM, Geisner IM, Cimini MD, Kilmer JR, Caldeira KM, Barrall AL, et al. Perceived academic benefit is associated with nonmedical prescription stimulant use among college students. Addict Behav. 2018;76:27-33. doi: 10.1016/j.addbeh.2017.07.013. [PubMed: 28735038]. [PubMed Central: PMC5614826].

6. Silveira Rda R, Lejderman B, Ferreira PE, Rocha GM. Patterns of non-medical use of methylphenidate among 5th and 6th year students in a medical school in southern Brazil. Trends Psychiatry Psychother. 2014;36(2):101-6. doi: 10.1590/2237-6089-2013-0065. [PubMed: 27000709].

7. Bjarnadottir GD, Haraldsson HM, Rafnar BO, Sigurdsson E, Steingrimsson S, Johannsson $\mathrm{M}$, et al. Prevalent intravenous abuse of methylphenidate among treatment-seeking patients with substance abuse disorders: A descriptive population-based study. J Addict Med. 2015;9(3):188-94. doi: 10.1097|ADM.0000000000000115. [PubMed: 25748561]. [PubMed Central: PMC4450903].

8. Joranson DE, Ryan KM, Gilson AM, Dahl JL. Trends in medical use and abuse of opioid analgesics. JAMA. 2000;283(13):1710-4. doi: 10.1001/jama.283.13.1710. [PubMed:10755497].

9. Jain R, Chang CC, Koto M, Geldenhuys A, Nichol R, Joubert G. Non-medical use of methylphenidate among medical students of the University of the Free State. S Afr J Psychiatr. 2017;23:1006. doi: 10.4102/sajpsychiatry.v23.1006. [PubMed: 30263181]. [PubMed Central: PMC6138185 may have inappropriately influenced them in writing this article].

10. Habibzadeh A, Alizadeh M, Malek A, Maghbooli L, Shoja MM, Ghabili K. Illicit methylphenidate use among Iranian medical students: Prevalence and knowledge. Drug Des Devel Ther. 2011;5:71-
6. doi: 10.2147/DDDT.S13818. [PubMed: 21340040]. [PubMed Central: PMC3038997].

11. Khademi L, Shariat SV. [Prevalence of nonmedical use of methylphenidate (ritalin) in Residents of Tehran University of Medical Sciences and their attitude toward methylphenidate use]. Iran J Psychiatry \& Clin Psychol. 2013;19(1):20-7. Persian.

12. Vakili F, Nilipour M. Illicit methylphenidate use in medical students of Najaf Abad Medical Sicence University. 2014.

13. Ataei M, Hosseini SN, Ahmadi Jouybari T, Jalilian F, Mirzaei Alavijeh M, Eslami AA, et al. [Application of prototype/willingness model in describe ritalin abuse behavior among college students]. J Health Syst Res. 2014;10(2):335-44. Persian.

14. Jalilian F, Karami-Matin B, Mirzaei Alavijeh M, Ataee M, Mahboubi M, Motlagh F, et al. Prevalence and factor related to ritalin abuse among Iranian medical college student: an application of theory of planned behavior. Terapevticheskii Arkhiv. 2013;85(4s):22-7.

15. Eslami AA, Jalilian F, Ataee M, Alavijeh MM, Mahboubi M, Afsar A, et al. Intention and willingness in understanding Ritalin misuse among Iranian medical college students: A cross-sectional study. Glob J Health Sci. 2014;6(6):43-53. doi: 10.5539/gjhs.v6n6p43. [PubMed: 25363098]. [PubMed Central: PMC4825534].

16. White BP, Becker-Blease KA, Grace-Bishop K. Stimulant medication use, misuse, and abuse in an undergraduate and graduate student sample. J Am Coll Health. 2006;54(5):261-8. doi: 10.3200/JACH.54.5.261268. [PubMed: 16539218].

17. Rezahosseini O, Roohbakhsh A, Tavakolian V, Assar S. Drug abuse among university students of Rafsanjan, Iran. Iran J Psychiatry Behav Sci. 2014;8(2):81-5. [PubMed: 25053961]. [PubMed Central: PMC4105608].

18. Finger G, Silva ER, Falavigna A. Use of methylphenidate among medical students: A systematic review. Rev Assoc Med Bras (1992). 2013;59(3):285-9. doi:10.1016/j.ramb.2012.10.007.[PubMed:23680277]. 